\title{
Spatial Spillover Effect of Strategic Emerging Industry Agglomeration and Green Economic Efficiency in China
}

\author{
Gang Zeng ${ }^{1,2}$, Chengxuan Geng ${ }^{1 *}$, Haixia Guo ${ }^{3 * *}$ \\ ${ }^{1}$ School of Economics and Management, Nanjing University of Aeronautics and Astronautics, Nanjing, China \\ ${ }^{2}$ School of Economics and Management, Civil Aviation University of China, Tianjin, China \\ ${ }^{3}$ School of Foreign Languages and Literature, Tianjin University, Tianjin, China
}

Received: 10 October 2019

Accepted: 11 January 2020

\begin{abstract}
Strategic emerging industries are key areas to promote industrial restructuring in China. Simultaneously, the government is focusing on the green economy for economic development. However, few studies have discussed the influence of strategic emerging industrial agglomeration on green economic efficiency. This study fills this gap based on the theory of location entropy and the super SBM model considering a non-expected output. A spatial Durbin model is introduced, and panel data of 30 provinces in China from 2012 to 2016 are selected to test the spatial spillover effect of strategic emerging industries on green economic efficiency. We found that: (1) China's overall strategic geographical spatial agglomeration shows a weakening trend from east to west, which is consistent with regional economic development, (2) green economic efficiency in most regions is below the forefront of production and economic, technological and labour input, (3) the direct effect of strategic emerging industrial agglomeration on green economic efficiency is significantly positive, the indirect effect is not significant, and the total effect is significantly positive, and (4) the direct, indirect, and total effects of economic development level, industrial structure, energy structure, foreign direct investment, and urbanization level on green economic efficiency are different.
\end{abstract}

Keywords: sustainable development, strategic emerging industries, agglomeration, green economic efficiency, spatial Durbin model, space spillover effect

\section{Introduction}

Strategic emerging industries are key areas for the Chinese government to promote industrial

\footnotetext{
*e-mail: gengchengxuan@126.com;
}

**e-mail: haixia.guo@tju.edu.cn restructuring and upgrading. In 2010, the State Council issued a "decision on accelerating the cultivation and development of strategic emerging industries" and subsequently formulated specific industrial policies during the $12^{\text {th }}$ and $13^{\text {th }}$ Five-Year Plans. Local governments at all levels have also implemented policies to support the sound development of strategic emerging industries by setting up special working groups and 
special funds, reducing or exempting them from taxes, and otherwise improving the financial environment. According to the 2018 Statistical Communique on National Economic and Social Development, the added value of China's strategic emerging industries increased by $11.7 \%$ in 2018 compared with 2017 . That same year, it produced 1.15 million new energy vehicles, 66.2\% more than in 2017. Smart TV production also reached 113.76 million units, $17.7 \%$ more than in 2017 . The scale effect of China's strategic emerging industries is becoming increasingly prominent, and the significance of their role in economic growth is rising. As for economic development, the Chinese government is attaching increasing importance to sustainability and green economic efficiency, which is an important index to measure the quality of economic development.

As strategic emerging industries are supported by China in the new era, do their spatial agglomeration play a role in promoting or hindering the efficiency of the regional green economy? Furthermore, due to the regional imbalance, strategic emerging industry clusters present the characteristics of the centre (edge). What is the concentration level of China's strategic emerging industries? Is there any regional heterogeneity in green economic efficiency? What is the spatial spillover effect of strategic emerging industrial agglomeration on green economic efficiency? Understanding these issues will help optimize the spatial distribution of strategic emerging industries and promote high-quality and sustainable economic growth.

Industrial agglomeration and green efficiency of the regional economy are current and prevalent concerns. After reviewing the literature, we found that most previous works study these two issues independently. Scholars have studied industrial agglomeration since the era of neoclassical economics. Weber (1909) and Hoover (1937) attempted to explain industrial agglomeration from the perspective of investment location. In 1980, Alfred Marshall creatively proposed the theory of industrial zones and used the concept of "agglomeration" to analyze the externalities generated by different concentrations of enterprises [1]. In the 1990s, many scholars began to study the interaction between technological innovation and economic growth of industrial agglomeration from the perspective of macroeconomics based on Schumpeter's innovation theory. Porter put forward the famous "diamond model." He believed that industrial agglomeration could help improve regional competitiveness, thus promoting rapid economic growth [2]. Smith et al. held that the connotation of industrial agglomeration lies in the scale effect and scope economy [3]. After 2000, with the rapid development of the industrial sector, many scholars focused on the relationship between industrial agglomeration and economic growth. Pan et al. found that manufacturing agglomeration significantly promoted regional economic growth by using the industrial agglomeration HHI index [4]. Based on the theory of externality, Sun et al. found that urban diversification promotes economic growth, but diversification hinders the development of small and medium-sized cities [5]. Wang et al. investigated industrial agglomeration in the Yangtze River economic belt and found that regional integration is conducive to promoting industrial agglomeration, reducing costs and achieving balanced employment [6]. Chen et al. found that industrial agglomeration has a positive spillover effect on the economic growth of a region, while it has a positive externality on the neighboring regions [7]. These studies link industrial agglomeration with macroeconomic growth and deeply analyze the influence mechanism and spatial effect of industrial agglomeration on the economy.

Amid serious environmental pollution and ecological destruction, green economic development is currently a hot topic in research. Pearce proposed the concept of a green economy in 1989 [8]. Regarding green economic efficiency, scholars have examined three main aspects. First is the efficiency evaluation of a green economy. Wang Jun et al. used the CCR method to estimate the green economic efficiency of 30 provinces and cities in China, and adopted the entropy weight method to select a comprehensive index of environmental pollution to calculate the output index [9]. Hua et al. used the SBM-undesirable and Malmquist model to estimate green efficiency and environmental total factor productivity, respectively, in 13 cities in Jiangsu Province [10]. Liu et al. designed a measurement model and method of enterprise eco-economic efficiency with the fuzzy set theory [11]. Second, research on the influence mechanism of green economic efficiency covers financial factors, outward foreign direct investment (OFDI), industrial structure, environmental regulation, and so on. SHI et al. studied the impact of financial agglomeration on urban green economic efficiency by using a panel threshold model and found that financial agglomeration effectively promoted urban green economic efficiency [12]. Gong et al. estimated the impact of OFDI's agglomeration effect on industrial green innovation efficiency and found that OFDI significantly promoted industrial green innovation efficiency through three mechanisms: agglomeration structure lightening effect, agglomeration economies of scale effect, and agglomeration resource allocation effect [13]. Qian et al. analyzed the spatial and temporal distribution characteristics and influencing factors of green efficiency and economic efficiency using industrial data of 285 prefecture-level cities in China from 2004 to 2015 and found that green economic efficiency has a U-shaped relationship with the level of economic development [14]. Third is the spatial convergence of green efficiency. Qian et al. hold that the efficiency of green economy among different provinces in China has conditional beta convergence, and technological progress is an important driver of efficiency improvement [15]. Hu et al. used the stochastic frontier approach (SFA) model to measure the green technology efficiency levels of various regions 
in China from 1996 to 2014, and found that the overall level was low using the spatial econometric model [16].

As the studies above show, most scholars pay attention to industrial agglomeration, economic growth, regional green economic efficiency, and their mutual relations. Existing research rarely discusses the influence of strategic emerging industrial agglomeration on green economic efficiency. In terms of the perspective of research methods, classic OLS regression model, the first-order difference generalized moment method of dynamic panel data and the system dynamic generalized moment estimation method (GMM) are mostly adopted for industrial agglomeration and regional economic growth results, and insufficient attention is paid to the spatial effect of industrial agglomeration. This study expands the traditional theory of industrial agglomeration by introducing the spatial econometric model and green efficiency model, and discusses the spatial spillover effect of strategic emerging industrial agglomeration on green economic efficiency. The location entropy method is used to measure the agglomeration of China's strategic emerging industries, and the Super SBM model proposed by Tone [17], considering non-expected output, is introduced to evaluate the efficiency of China's provincial green economy. Finally, the dynamic spatial Durbin model is used to empirically test the spatial spillover effect between strategic emerging industrial agglomeration and green economic efficiency. The results provide policy support for high-quality sustainable development of China's economy in a period of transformation and upgrading.

\section{Experimental}

\section{Measurement of Agglomeration Level of Strategic Emerging Industries}

The measurement of the industrial agglomeration level is an important issue in regional economics. In 1936, Hoover modified the Lorenz curve and proposed the Hoover coefficient [18]. The spatial GINI index (proposed by Krugman), EC index (proposed by Ellison and Glaeser), and $\mathrm{HH}$ index (proposed by Herfindal and Hirschmann) are also widely used. In 1996, Cliff et al. proposed the location entropy theory, which uses location entropy to evaluate the advantageous industries of a region and the degree of specialization of an industry [19]. Location entropy has unique convenience and explanatory power to reflect the spatial distribution of industrial elements. Therefore, this study adopts the location entropy method to evaluate the measurement of strategic emerging industrial agglomeration [20]. The calculation is as follows:

$$
\operatorname{MAR}=\frac{x_{i j}}{\sum_{i=1}^{m} x_{i j}} / \frac{\sum_{j=1}^{n} x_{i j}}{\sum_{i=1}^{m} \sum_{j=1}^{n} x_{i j}}
$$

In Equation (1), $\mathrm{x}_{\mathrm{ij}}$ represents the total revenue of the main business of strategic emerging industry $\mathrm{i}$ in region $\mathrm{j} ; \sum_{\mathrm{i}=1}^{\mathrm{n}} \mathrm{x}_{\mathrm{ij}}$ represents the total revenue of the main business of strategic emerging industries in region $\mathrm{j} ; \sum_{\mathrm{j}=1}^{\mathrm{n}} \mathrm{x}_{\mathrm{ij}}$ represents the total revenue of the main business of strategic emerging sub-industry $i$ in China; and $\sum_{\mathrm{i}=1}^{\mathrm{m}} \sum_{\mathrm{j}=1}^{\mathrm{n}} \mathrm{x}_{\mathrm{ij}}$ represents the total revenue of all strategic emerging industries in China. MAR reflects the agglomeration degree of strategic emerging industries in an area. The higher the MAR, the higher the agglomeration degree, and vice versa.

\section{Evaluation Model of Green Economic Efficiency}

The data envelopment analysis (DEA) model is the first non-parametric efficiency estimation method proposed by Harnes et al., which has the advantage of avoiding human error without prior parameter estimation. Since the evaluation of green economic efficiency needs to consider the impact of external undesired environmental output, this study chooses the method of the undesired DEA model for efficiency evaluation. Currently, the commonly used nonexpected evaluation methods include the input-output inversion method, directional distance function, and forward attribute. However, as these methods have the disadvantage of "slack" input-output, this study uses the super SBM proposed by Tone to measure green economic efficiency. This method absorbs the advantages of the SBM model and constructs production possibility sets of expected and non-expected outputs, thus avoiding the problem of the "slack" of the input and output. Moreover, this method allows for the efficiency value of effective units to be greater than or equal to 1 in order to achieve the purpose of sorting comparison of effective decision units. Thus, this study's mathematical model of regional economic green is as follows [21-23]:

$$
\begin{gathered}
\min \left[\theta-\varepsilon\left(\sum_{i=1}^{m} s_{i}{ }^{-}+\sum_{t=1}^{s} s_{i}{ }^{-}\right)\right] \\
\text {s.t. } \sum_{n} X_{i j} \lambda_{j}+s_{i}{ }^{-} \leq \theta X_{0} \\
\sum_{n} Y_{j} \lambda_{j}-s_{t}{ }^{+} \equiv Y_{0} \\
\lambda_{j} \geq 0, j=1,2, \ldots, n, s_{i}{ }^{-} \geq 0, s_{t}{ }^{+} \geq 0
\end{gathered}
$$

In Equation (2), $\mathrm{s}_{\mathrm{t}}^{+}$and $\mathrm{s}_{\mathrm{i}}^{-}$represent the excess of input index and the loss of output index respectively; $\lambda_{j}$ represents the weight coefficient of correlation calculation; and $\varepsilon$ is the non-Archimedes infinitesimal.

Green economic efficiency considers both economic benefits and ecological benefits. The Super SBM model can be used to evaluate the impact of economic benefit factors through the expected output, while the non-expected output can be used to investigate the impact of environmental factors. Therefore, based on the connotations of green economic efficiency and the 
Table 1. Green economic efficiency input-output index system.

\begin{tabular}{|c|c|c|}
\hline \multirow{2}{*}{ Indicators } & Level indicators & Secondary indicators \\
\hline \multirow{2}{*}{ Input } & Labour input & Total employment in each region \\
\cline { 2 - 3 } & Capital investment & Capital stock perpetual inventory method \\
\cline { 2 - 3 } & The energy input & Total energy consumption \\
\hline Expect output & Regional GDP & Regional GDP per capita \\
\hline \multirow{2}{*}{ Undesired output } & Environmental pollution index & Industrial emission \\
\cline { 2 - 3 } & & Total discharge of industrial wastewater \\
\cline { 2 - 3 } & & Industrial solid waste discharge \\
\hline
\end{tabular}

needs of the Super SBM model, some results serve as a reference for the construction of a green economic efficiency input-output index system (see Table 1).

\section{Input Indicators}

Based on the Cobb-Douglas production function method, labor, capital, and energy are selected as the first-level input indicators. It is difficult to evaluate labor directly; thus, this study selects the total number of actual employees at the end of the year as the secondlevel evaluation index based on available data. Learning from previous studies, capital investment is calculated by the perpetual inventory method; for energy input, energy consumption is considered. Data are obtained from a statistical yearbook, and energy measurement is converted into standard coal.

\section{Output Indicators}

Expected output considers economic benefits with regional GDP and per capita GDP as the first-level and second-level evaluation indexes, respectively. The non-expected output considers sources of industrial pollution; selects the relevant data for industrial waste (gas, sewage, and solid waste emissions); and uses the entropy method to obtain a comprehensive index of environmental pollution.

\section{Exploratory Spatial Data Analysis}

The influence mechanism of strategic emerging industrial agglomeration on the regional economy is mainly reflected in the scale effect and scope economy effect caused by agglomeration, which can promote efficient allocation of regional knowledge, technology, talents, and other elements; reduce production consumption and cost; and promote professional division of labor and a supportive economic environment. Therefore, learning from TANG J. et al. [24], we first study the spatial autocorrelation law of green economic efficiency in China using the exploratory spatial data analysis (ESDA) method and construct an appropriate spatial econometric model to analyze the internal logical relationship between strategic emerging industrial agglomeration and green economic efficiency.

The ESDA verifies the geographical clustering characteristics between different spatial data. In 1950, Patrick Alfred Pierce Moran proposed Moran's I index to measure spatial correlation. This study uses this method to analyze the global spatial autocorrelation of China's green economic efficiency with global Moran's I statistics and applies the local Moran index to analyze the local spatial correlation of green economic efficiency in different regions of China [25-27].

(1) The mathematical expression of global Moran's I index is:

$$
\mathrm{I}=\frac{\sum_{i=1}^{n} \sum_{j=1}^{n} w_{i j}\left(x_{i}-\bar{x}\right)\left(x_{j}-\bar{x}\right)}{S^{2} \sum_{i=1}^{n} \sum_{j=1}^{n} w_{i j}}
$$

Among them, $\mathrm{S}^{2}=\frac{1}{\mathrm{n}} \sum_{\mathrm{i}=1}^{\mathrm{n}}\left(\mathrm{x}_{\mathrm{i}}-\overline{\mathrm{x}}\right)^{2} ; \overline{\mathrm{x}}=\frac{1}{\mathrm{n}} \sum_{\mathrm{i}=1}^{\mathrm{n}} \mathrm{x}_{\mathrm{i}}$ Moran's I is between $[-1,1]$; if the value is equal to 0 , the space is irrelevant; if the value is greater than 0 and close to 1 , the positive spatial correlation is stronger. Similarly, if the value is less than 0 and closer to -1 , the negative spatial correlation is stronger.

(2) The mathematical expression of local Moran's I index is:

$$
I_{i}=\frac{\left(x_{i}-\bar{x}\right)}{S^{2}} \sum_{j} w_{i j}\left(x_{i}-\bar{x}\right)
$$

According to the above equation, if $\mathrm{I}_{i}>0$, the region and the neighbouring region have similar characteristics and vice versa. Local Moran's I index can be visually displayed using a scatter diagram.

\section{Space Panel Measurement Model Setting}

What is the spatial spillover effect of strategic emerging industrial agglomeration on green economic efficiency? This study will use the method of space measurement for verification. In addition, regional green economic efficiency (GEE) is affected not only by strategic emerging industrial agglomeration (MAR), 
but also by other external factors, including the level of economic development (AGDP), industrial structure (IND), energy structure (ES), foreign investment (FDI), and urbanization level (UR), according to REN et al. [28]. The spatial lag model (SLM), spatial error model (SEM), and spatial Durbin model (SDM) are three commonly used spatial models.

\section{Spatial Lag Model (SLM)}

The SLM focuses on the influence of green economic efficiency of a region on that of adjacent regions - that is, the spatial spillover effect between regions. The mathematical formula is:

$$
\begin{gathered}
\text { gee }_{i t}=C+\rho \text { Wgee }_{i t}+\beta_{0} \mathrm{IA}_{\mathrm{it}}+\beta_{1} \mathrm{AGDP}_{\mathrm{it}} \\
+\beta_{2} \mathrm{IND}_{\mathrm{it}}+\beta_{3} \mathrm{ES}_{\mathrm{it}}+\beta_{4} \mathrm{FDI}_{\mathrm{it}}+\beta_{5} \mathrm{UR}_{\mathrm{it}} \\
+\alpha_{\mathrm{i}}+\mu_{\mathrm{i}}+\varepsilon_{\mathrm{it}}
\end{gathered}
$$

Among them, $\varepsilon_{\mathrm{it}} \sim \mathrm{N}\left(0, \sigma_{\mathrm{it}}^{2} \mathrm{I}_{\mathrm{n}}\right)$.

\section{Spatial Error Model (SEM)}

Apart from the influence on green economic efficiency, the spatial effect may be reflected in the error term, that is, there may be some missing variables or spatial correlation of the error term. The model can be expressed as:

$$
\begin{aligned}
\text { gee }_{\text {it }}=\mathrm{C} & +\beta_{0} \mathrm{IA}_{\mathrm{it}}+\beta_{1} \mathrm{AGDP}_{\mathrm{it}}+\beta_{2} \mathrm{IND}_{\mathrm{it}}+\beta_{3} \mathrm{ES}_{\mathrm{it}} \\
& +\beta_{4} \mathrm{FDI}_{\mathrm{it}}+\beta_{5} \mathrm{UR}_{\mathrm{it}}+\alpha_{\mathrm{i}}+\mu_{\mathrm{t}}+\varepsilon_{\mathrm{it}}
\end{aligned}
$$

Among them, $\varepsilon_{\mathrm{it}}=\lambda \mathrm{W} \varepsilon_{\mathrm{it}}+\varphi_{\mathrm{it}} ; \varphi_{\mathrm{it}} \sim \mathrm{N}\left(0, \sigma_{\mathrm{it}}^{2} \mathrm{I}_{\mathrm{n}}\right)$.

\section{Spatial Durbin Model (SDM)}

It considers the spatial hysteresis of both dependent and independent variables of green economic efficiency. The model is set as follows:

$$
\begin{gathered}
\text { gee }_{\text {it }}=\mathrm{C}+\rho \mathrm{Wgee}_{\mathrm{it}}+\beta_{0} \mathrm{IA}_{\mathrm{it}}+\beta_{1} \mathrm{AGDP}_{\mathrm{it}}+\beta_{2} \mathrm{IND}_{\mathrm{it}} \\
+\beta_{3} \mathrm{ES}_{\mathrm{it}}+\beta_{4} \mathrm{FDI}_{\mathrm{it}}+\beta_{5} \mathrm{UR}_{\mathrm{it}}+\theta_{0} \mathrm{WIA}_{\mathrm{it}}+\theta_{1} \mathrm{WAGDP}_{\mathrm{it}} \\
+\theta_{2} \mathrm{WIND}_{\mathrm{it}}+\theta_{3} \mathrm{WES}_{\mathrm{it}}+\theta_{4} \mathrm{WFDI}_{\mathrm{it}}+\theta_{5} \mathrm{WUR}_{\mathrm{it}} \\
+\alpha_{\mathrm{i}}+\mu_{\mathrm{t}}+\varepsilon_{\mathrm{it}}
\end{gathered}
$$

Among them, $\varepsilon_{\mathrm{it}} \sim \mathrm{N}\left(0, \sigma_{\mathrm{it}}^{2} \mathrm{I}_{\mathrm{n}}\right)$

In models (5)-(7), $\mathrm{i}$ represents the region, $\mathrm{t}$ represents the time, $\beta_{0} \sim \beta_{5}$ represent the coefficients of the explanatory variables; $\varepsilon$ represents the random disturbance term; W represents spatial weight matrix; $\alpha_{i}$ represents the spatial trait effect; and $\mu_{t}$ represents the period trait effect.

As for the selection of the above three models, the Wald and LR tests are used to examine the null hypothesis $\mathrm{H}_{0:} \theta=0$ and $\mathrm{H}_{0:} \theta+\rho \beta=0$. If the null hypothesis is rejected, the spatial Durbin model is used; otherwise, the other two models are selected for comparison.

\section{Variable Selection and Data Sources}

This study is based on data accessibility and continuity, representativeness of indicators, and existing studies $[22,24,29]$, and the main sample area covers 30 provinces and autonomous regions in mainland China. The research period is from 2012 to 2016. Due to the long inter-period and great range of data, missing values or abnormal data appear in some observations (Hong Kong, Macao, Taiwan, and Tibet are excluded due to missing dates or incomplete data). Therefore, this study adopts a linear difference, multiple interpolations, homogeneous mean, and same-year data substitution method in neighbouring regions to correct these issues.

\section{Data Description of the Agglomeration Level of Strategic Emerging Industries}

Due to China's short history of industrial development, it does not yet have authoritative statistical methods for measuring strategic emerging industries. However, China has established a standardized and official statistical system for measuring high-tech industries. As many high-tech industries are strategic emerging industries, the data for measuring the agglomeration level of strategic emerging industries are taken from China's statistical yearbook of high and new technologies.

\section{Sources of Input and Output Data for Measuring Green Economic Efficiency}

These include the China Population and Employment Statistical Yearbook, China Energy Statistical Yearbook, China Statistical Yearbook, and China Environmental Statistical Yearbook.

\section{Spatial Panel Measurement Model Variable Selection and Data Source}

As shown in Table 2, the explained variable includes green economic efficiency and data source is the Super SBM model. The explanatory variables are as follows:

1. The industrial agglomeration level, which is calculated according to the location entropy model.

2. The level of economic development, which is the quality of economic development as an important symbol of regional economic growth; the selection of per capita GDP can fully reflect regional economic level.

3. The industrial structure, that is, increasing the proportion of the tertiary industry, is the focus of China's supply-side reform. Therefore, the proportion of the added value of the tertiary industry in GDP is adopted to evaluate the industrial structure. 
Table 2. Index selection and data sources.

\begin{tabular}{|c|c|c|c|c|}
\hline Variable & Indicators & Calculation method & Code & Data source \\
\hline $\begin{array}{l}\text { Explained } \\
\text { variable }\end{array}$ & Green economic efficiency & Super - SBM is calculated & Gee & Model calculation \\
\hline \multirow{6}{*}{$\begin{array}{c}\text { Explanatory } \\
\text { variables }\end{array}$} & $\begin{array}{c}\text { Industrial agglomeration } \\
\text { level }\end{array}$ & Location entropy & MAR & Model calculation \\
\hline & $\begin{array}{l}\text { Level of economic } \\
\text { development }\end{array}$ & GDP per capita & AGDP & $\begin{array}{l}\text { Statistical yearbook of each } \\
\text { province }\end{array}$ \\
\hline & The industrial structure & $\begin{array}{l}\text { The added value of tertiary industry } \\
\text { accounts for the proportion of GDP }\end{array}$ & IND & $\begin{array}{l}\text { Statistical yearbook of each } \\
\text { province }\end{array}$ \\
\hline & The energy structure & $\begin{array}{c}\text { Coal accounts for the total amount of } \\
\text { energy consumed }\end{array}$ & ES & China energy statistical yearbook \\
\hline & Foreign direct investment & Foreign direct investment & FDI & $\begin{array}{l}\text { Statistical yearbook of each } \\
\text { province }\end{array}$ \\
\hline & Urbanisation level & $\begin{array}{l}\text { The proportion of urban population in } \\
\text { the total population }\end{array}$ & UR & $\begin{array}{l}\text { Statistical yearbook of each } \\
\text { province }\end{array}$ \\
\hline
\end{tabular}

4. Energy structure. Coal is the most important energy source consumed in China; thus, the energy structure is evaluated by using the proportion of coal consumption in total energy consumption, in which the two are converted into the ratio of standard coal.

5. Foreign direct investment. The introduction of foreign investors is an important measure for China to open to the world and promote economic development. The role of foreign investment in the efficiency of the green economy is uncertain. This study selects foreign direct investment to measure.

6. Urbanization level. Cities have advantages in capital and technology in terms of resources and environmental governance, which is conducive to improving green economic efficiency. Therefore, the proportion of urban population in the total population of the region is selected as the evaluation index. The data sources for the above indicators are the China Energy Statistical Yearbook and local statistical yearbooks of various provinces and cities.

\section{Results and Discussion}

\section{Cluster Level Analysis of Strategic Emerging Industries}

Equation (1) is used to substitute relevant data to obtain China's strategic emerging industrial agglomeration from 2012 to 2016, as shown in Table 3 . From the point of statistical average, provinces and cities with location entropy greater than 1.0 include Guangdong (2.62), Jiangsu (2.35), Shandong (1.86), Shanghai (1.55), Sichuan (1.37), Zhejiang (1.34), Henan (1.32), Beijing (1.15), Tianjin (1.13), Fujian (1.08), and Chongqing (1.03). It reveals that strategic emerging industries are highly concentrated in these regions and are in good development, especially Guangdong and Jiangsu, which take the lead. Guangdong province has
15 national high-tech industrial bases and 42 provincial strategic emerging industrial bases, forming several emerging industrial clusters with output value exceeding 100 billion yuan. During the $12^{\text {th }}$ Five-Year Plan, the invention patents of strategic emerging industries in Jiangsu province accounted for more than $40 \%$ of the province's total patents, and there were more than 2,300 national and provincial innovation platforms. The market value of over 75 strategic emerging industries exceeded 10 billion yuan, accounting for more than $60 \%$ of the province's total. Meanwhile, the regional entropy values of Inner Mongolia, Yunnan, Gansu province, Qinghai, Ningxia, and Xinjiang are all lower than 0.6 , which are $0.56,0.54,0.49,0.33,0.32$ and 0.29 , respectively. The agglomeration effect of the strategic emerging industries is not significant. The locational entropy of Hubei, Hunan, Jiangxi, Anhui, and Liaoning is between 0.8 and 1.0, and the development of strategic emerging industries has a large growth space.

Geographically, China's strategic emerging industry cluster as a whole shows a weakening trend from east to west, which is matched by regional economic growth. By virtue of the scale effect of industrial agglomeration, the eastern region further reduces the operating cost of enterprises, expands economic benefits, and forms a benign development mode for strategic emerging industries. Although the development of strategic emerging industries in the central and western regions has disadvantages, strategic emerging industries are an important way to achieve regional economic breakthroughs. For example, although Shaanxi and Guizhou are located in the western region, the agglomeration effect of strategic emerging industries continues to be prominent. During the sample period, the locational entropy of Guizhou is $0.55,0.56,0.59$, 0.69 and 0.72 , respectively. The locational entropy of Shaanxi is $0.75,0.73,0.76,0.80$ and 0.83 , respectively, maintaining the growth trend. Guizhou has made great efforts to develop the big data industry. It built 
Table 3. Location entropy index of strategic emerging industries from 2012 to 2016.

\begin{tabular}{|c|c|c|c|c|c|c|c|}
\hline Serial number & Province & 2012 & 2013 & 2014 & 2015 & 2016 & Mean \\
\hline 1 & Beijing & 1.05 & 1.06 & 1.22 & 1.20 & 1.23 & 1.15 \\
\hline 2 & Tianjin & 1.02 & 1.07 & 1.26 & 1.25 & 1.03 & 1.13 \\
\hline 3 & Hebei & 0.73 & 0.74 & 0.75 & 0.76 & 0.78 & 0.75 \\
\hline 4 & Shanxi & 0.66 & 0.67 & 0.68 & 0.70 & 0.73 & 0.69 \\
\hline 5 & NeiMongol & 0.53 & 0.55 & 0.57 & 0.58 & 0.55 & 0.56 \\
\hline 6 & Liaoning & 0.88 & 0.87 & 0.87 & 0.78 & 0.73 & 0.83 \\
\hline 7 & Jilin & 0.71 & 0.75 & 0.79 & 0.81 & 0.82 & 0.78 \\
\hline 8 & Heilongjiang & 0.60 & 0.63 & 0.65 & 0.63 & 0.58 & 0.62 \\
\hline 9 & Shanghai & 1.62 & 1.36 & 1.63 & 1.64 & 1.49 & 1.55 \\
\hline 10 & Jiangsu & 2.20 & 2.18 & 2.38 & 2.45 & 2.55 & 2.35 \\
\hline 11 & Zhejiang & 1.21 & 1.28 & 1.37 & 1.42 & 1.44 & 1.34 \\
\hline 12 & Anhui & 0.76 & 0.79 & 0.88 & 0.93 & 1.01 & 0.87 \\
\hline 13 & Fujian & 0.93 & 0.92 & 1.05 & 1.18 & 1.32 & 1.08 \\
\hline 14 & overall & 0.79 & 0.82 & 0.89 & 0.92 & 1.02 & 0.89 \\
\hline 15 & Shandong & 1.80 & 1.78 & 1.89 & 1.90 & 1.92 & 1.86 \\
\hline 16 & Henan & 0.99 & 1.08 & 1.43 & 1.51 & 1.58 & 1.32 \\
\hline 17 & Hubei & 0.87 & 0.88 & 0.91 & 1.02 & 1.08 & 0.95 \\
\hline 18 & Hunan & 0.80 & 0.89 & 0.90 & 0.97 & 1.02 & 0.92 \\
\hline 19 & Guangdong & 2.30 & 2.46 & 2.66 & 2.78 & 2.88 & 2.62 \\
\hline 20 & Guangxi & 0.68 & 0.69 & 0.71 & 0.77 & 0.79 & 0.73 \\
\hline 21 & Hainan & 0.43 & 0.41 & 0.42 & 0.43 & 0.43 & 0.42 \\
\hline 22 & Chongqing & 0.81 & 0.78 & 0.95 & 1.21 & 1.38 & 1.03 \\
\hline 23 & Sichuan & 1.19 & 1.35 & 1.46 & 1.40 & 1.45 & 1.37 \\
\hline 24 & Guizhou & 0.55 & 0.56 & 0.59 & 0.69 & 0.72 & 0.62 \\
\hline 25 & Yunnan & 0.52 & 0.53 & 0.54 & 0.56 & 0.57 & 0.54 \\
\hline 26 & Shaanxi & 0.75 & 0.73 & 0.76 & 0.80 & 0.83 & 0.77 \\
\hline 27 & Gansu & 0.45 & 0.49 & 0.50 & 0.51 & 0.52 & 0.49 \\
\hline 28 & Qinghai & 0.33 & 0.32 & 0.33 & 0.34 & 0.34 & 0.33 \\
\hline 29 & Ningxia & 0.31 & 0.31 & 0.32 & 0.33 & 0.35 & 0.32 \\
\hline 30 & Xinjiang & 0.26 & 0.28 & 0.29 & 0.30 & 0.31 & 0.29 \\
\hline
\end{tabular}

China's first national comprehensive big data pilot zone, attracting first-class enterprises such as Microsoft, Google, China Mobile, China telecom, China Unicom, Alibaba, Jingdong, Tencent, and Baidu. Shaanxi has achieved a leading status at the international level in the fields of satellite navigation, ceramic matrix composite materials, unmanned aerial vehicle systems, superconducting materials, visual information processing, ultra-high voltage power transmission, and transformation. It has attracted well-known international enterprises such as Honeywell, General Electric, and Rolls-Royce.

\section{Green Economic Efficiency Measurement Results}

We use MAXDEA professional software to calculate the green economic efficiency of 30 provinces and autonomous regions in China from 2012 to 2016. According to the calculation results, in addition to the mean value of five years in the sample period, only Shanghai and Beijing have a mean value greater than 1.0 , which is 1.45 and 1.16 respectively, and they are on the frontier of green economic efficiency production. The green economic efficiency of other provinces is 


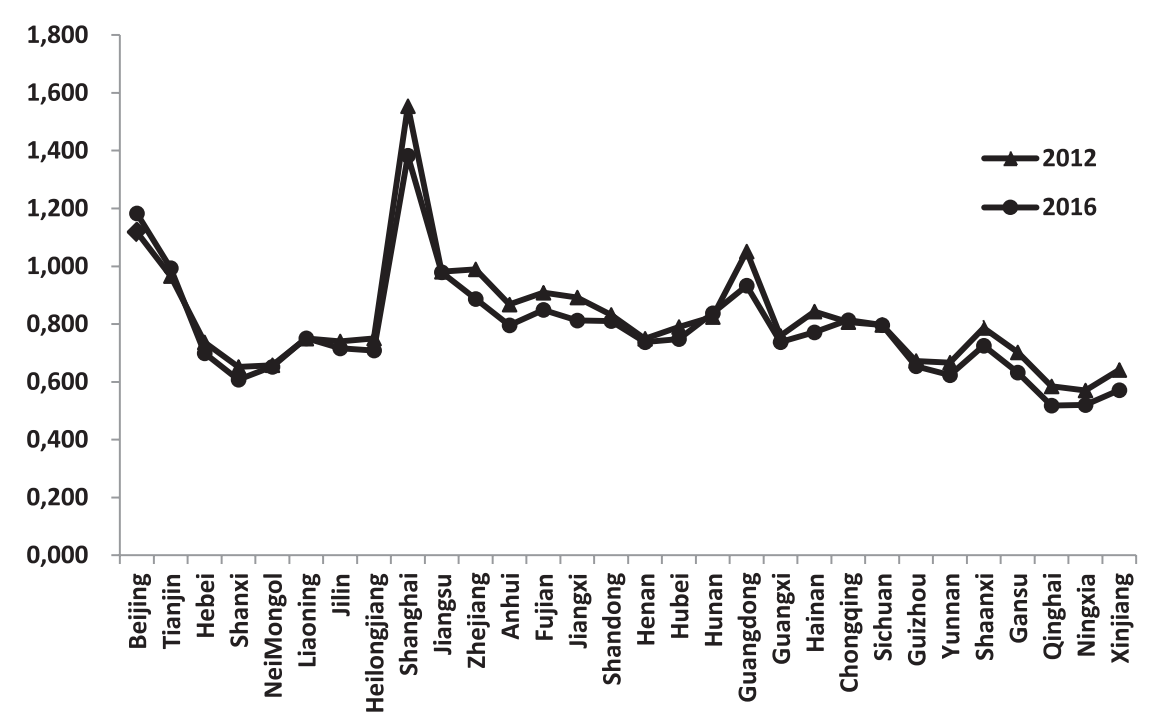

Fig. 1. Efficiency measurement results of China's green economy.

invalid, which shows that labour, capital, and energy investment in most parts of China are redundant, and there is no coordinated development model between economic, technological, labour and other resources and the environment.

Green economic efficiency in Jiangsu, Guangdong, Tianjin and Zhejiang is $0.98,0.97$ and 0.97 , respectively. The overall efficiency of these provinces and cities is close to full effectiveness, and the structure of each input factor of efficiency is reasonable. Xinjiang, Ningxia, and Qinghai are the three regions with the lowest green economic efficiency, with an average of less than 0.6 , which reveals serious redundancy of input or shortage of output. Thus, improving the economic output of these regions and reducing environmental pollution and other unexpected outputs is an effective way to improve green economic efficiency in these regions. In addition, the average green economic efficiency of 16 provinces and cities - including Hebei, Heilongjiang, Jilin, Henan, Guangxi, Liaoning, Hubei, Shanxi, Hainan, Sichuan, Anhui, Shandong, Chongqing, Jiangxi, Hunan, and Fujian - ranged from 0.71 to 0.87 , accounting for $53.3 \%$ of the total sample. This result suggests that China should not only achieve the goal of economic growth but also intensify efforts to promote transformation and upgrading of industry, ultimately achieving green growth.

Finally, as shown in Fig. 1, in terms of time, the green economic efficiency levels in 2012 and 2016 basically have the same trend, while in terms of the degree of change, green economic efficiency has declined slightly. However, China's economy has maintained rapid growth in recent years. For example, China's GDP reached 7,4412.7 billion yuan in 2016 an increase of $6.7 \%$ as compared to 2015 , among which the primary, secondary, and tertiary industries grew by $3.3 \%, 6.1 \%$, and $7.8 \%$ respectively. This reveals that although China's macroeconomy maintained rapid growth, environmental pollution has become increasingly serious, and green economic efficiency has not improved. By using structural reforms, closing backward production facilities, and vigorously developing strategic emerging industries to realise green status, high-quality economic growth has become a new mode of China's economic development.

\section{Spatial Autocorrelation Analysis}

According to the ESDA method, this study first examines whether there is spatial dependence among the green economic efficiency of the 30 provinces. This part uses GeoDa, a spatial measurement and statistics software, for calculation.

\section{Global Spatial Autocorrelation Analysis}

As shown in Table 4, the spatial weight matrix is set as the first-order Rook adjacency matrix to obtain the global Moran's I index of green economic efficiency. According to the statistical results, from 2012 to 2016 Moran's I index is between 0.1005 and 0.0889 , both of which are greater than 0 . The index from 2012 to 2016 is significant at the $1 \%$ level, and at the $5 \%$ level from 2013 to 2015, which indicates that there is a positive spatial correlation between strategic emerging industrial agglomeration and green economic efficiency.

\section{Local Spatial Autocorrelation Analysis}

Limited by length, partial Moran's I scatter plots of 2012 and 2016 are selected for analysis. As shown in Figs 2 and 3, during the sample period, most of Moran's I indexes of the 30 provinces fall into the first and third quadrants, showing the characteristics of high-high agglomeration and low-low agglomeration, which indicates that green economic efficiency has spatial heterogeneity among different provinces. Meanwhile, local Moran's I index values are all greater 
Table 4. Global green efficiency of China's economy Moran's I index.

\begin{tabular}{|c|c|c|c|c|c|}
\hline Year & Moran's I index & Expectations & The variance & Z statistic & P values \\
\hline 2012 & 0.0540 & 0.0280 & 0.1141 & 3.7186 & 0.002 \\
\hline 2013 & 0.0787 & 0.0253 & 0.1096 & 3.9487 & 0.039 \\
\hline 2014 & 0.0834 & 0.0246 & 0.1103 & 3.9786 & 0.047 \\
\hline 2015 & 0.0889 & 0.0247 & 0.1100 & 4.0327 & 0.016 \\
\hline 2016 & 0.1005 & 0.0245 & 0.1102 & 4.1344 & 0.006 \\
\hline
\end{tabular}

(Note: Rook adjacency weight matrix was selected to carry out relevant measurement)

than 0 , indicating that the green economic efficiency has local correlations in geographical space. Therefore, geographical space factors play a significant role.

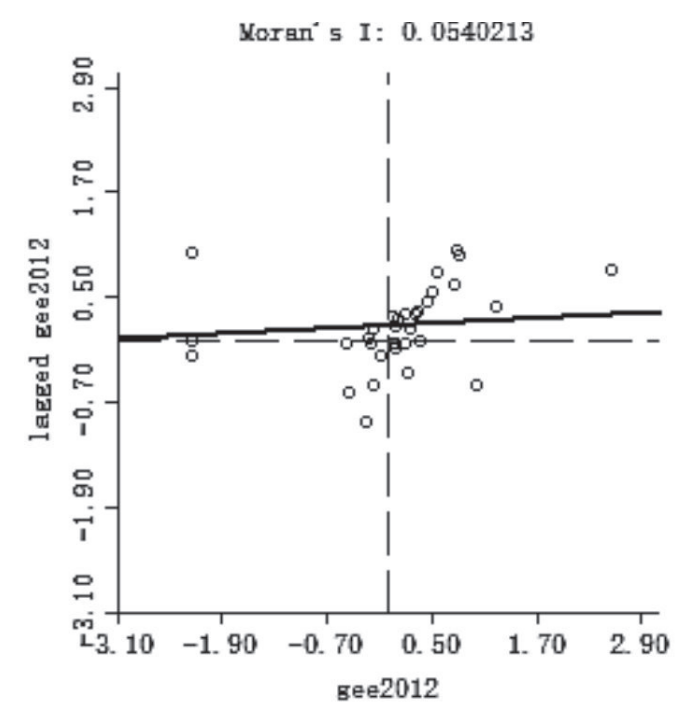

Fig. 2. Partial Moran's I scatter diagram of green efficiency in 2012.

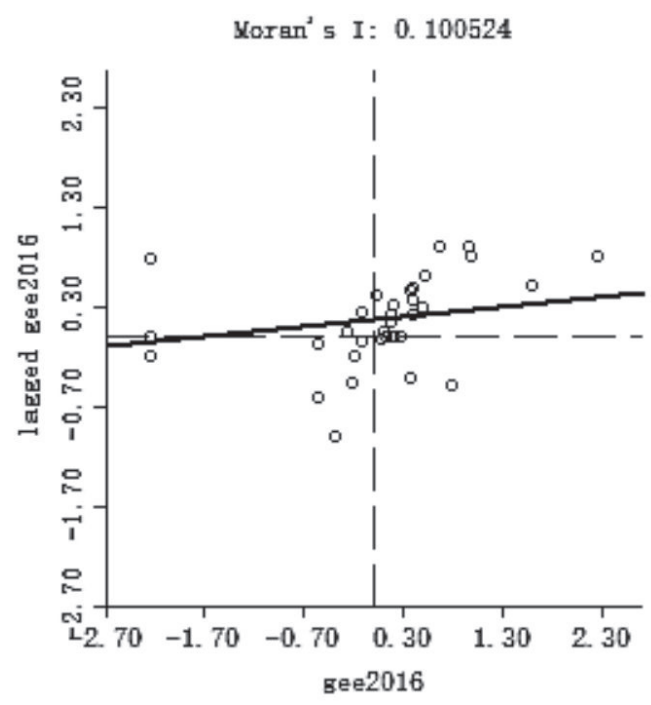

Fig. 3. Partial Moran's I scatter diagram of green efficiency in 2016.
Furthermore, from the LISA agglomeration map of green economic efficiency, as shown in Figs 4 and 5, the eastern coastal region presents a significant spatial feature of "high-high agglomeration," while the western region presents a feature of "low-low agglomeration." This situation is in line with the current situation of China's economic development. The eastern region has a high economic level and advanced technology, which has formed unique advantages in terms of resources and environmental protection. In the western region, economic development does not have geographical advantages. Meanwhile, the desertification therein leads to a poor natural environment and low efficiency of green economy.

\section{Analysis of Spatial Econometric Model Results}

The above ESDA analysis shows that there is spatial autocorrelation between different regions of China's green economic efficiency. Therefore, in the next stage, the focus is to select an appropriate spatial econometric

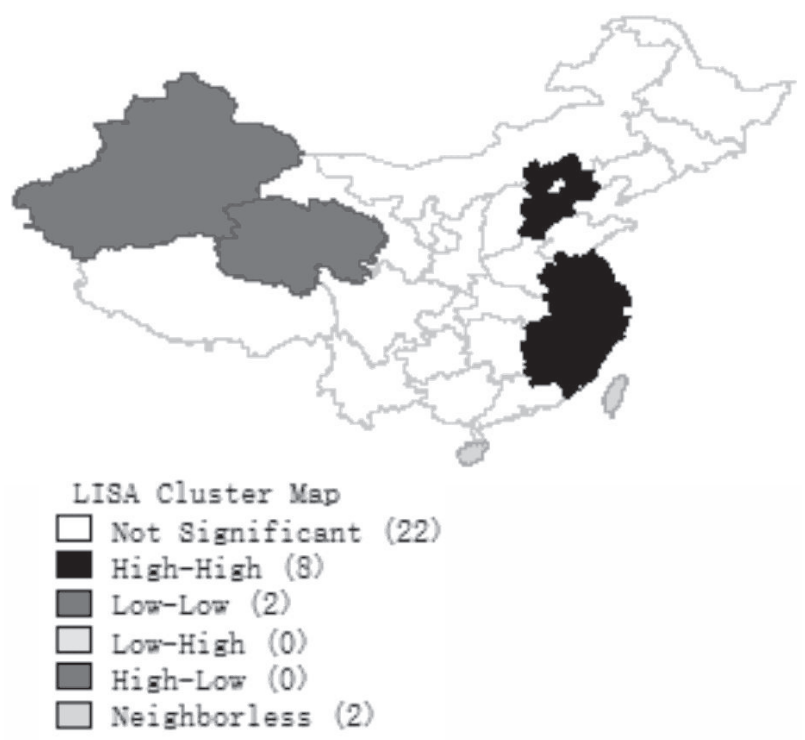

Fig. 4. LISA agglomeration map of China's green economic efficiency in 2012. 


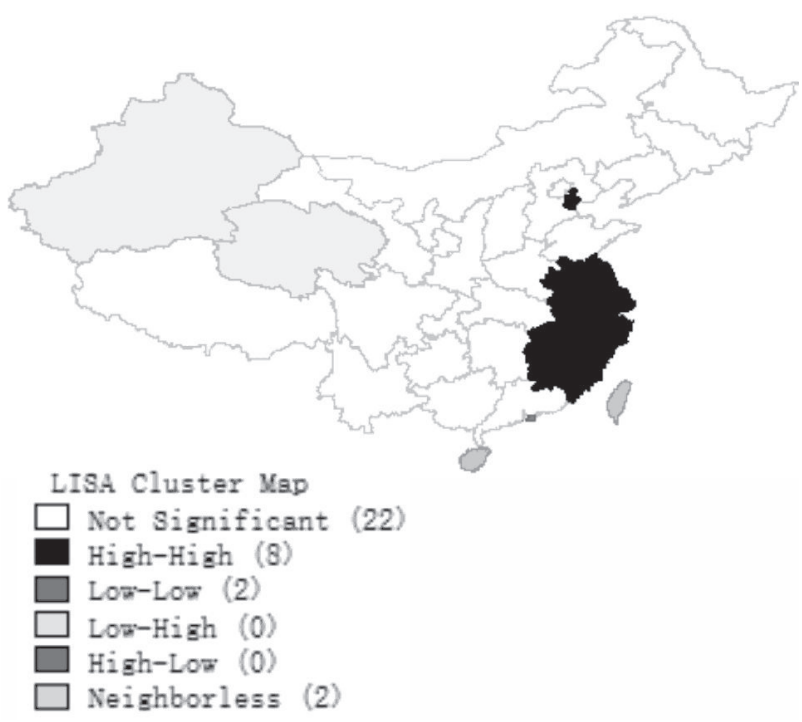

Fig. 5. LISA agglomeration map of China's green economic efficiency in 2016.

model to explore the spatial spillover effect of strategic emerging industrial agglomeration on China's green economic efficiency. All quantitative analyses in this section were performed using STATA 14.0 software.

\section{Data Processing, Variable Testing, and Model Selection}

First, to reduce heteroscedasticity, logarithms of all explanatory and explained variables in Equations (5) to (7) are taken. Before the formal estimation, the variance expansion factor of the variable was calculated, which gave an average value of 2.58 and a maximum value of 8.33 ; thus, there was no multicollinearity between variables. The final decision is to either choose the random effect model or the fixed effect model. The Hausman test is used to determine the better approach. According to the calculation results, chi2(6) $=16.52$ and $\mathrm{P}=0.0112$, which is significant at the $5 \%$ level. Therefore, the null hypothesis is rejected. This study employs the time-space double fixed effect model for estimation.

\section{The Choice of Spatial Lag Model, Spatial Error Model, or Spatial Durbin Model}

The efficiency of China's green economy has spatial spillover. How to choose an appropriate spatial econometric model is one of the keys to research. The spatial lag model focuses on the spatial correlation of explained variables and the spatial error model focuses on the influence of the random disturbance term, both of which are special forms of the spatial Durbin model [22]. Therefore, the criterion proposed by Burridge can be used for reference on whether the space Durbin model can be reduced to two other models. The null hypothesis is $\mathrm{H}_{0}: \theta=0$ and $\mathrm{H}_{1}: \theta+\delta \beta=0$. The Wald
Table 5. Wald and LR test results of dual-fixed SDM model.

\begin{tabular}{|c|c|}
\hline Inspection & Time-space dual fixed SDM model \\
\hline LR_spatial_lag & $\begin{array}{c}17.15^{* * *} \\
(0.0087)\end{array}$ \\
\hline Wald_spatial_lag & $\begin{array}{c}10.218^{* * *} \\
(0.001)\end{array}$ \\
\hline LR_spatial_error & $\begin{array}{c}14.89^{* *} \\
(0.0211)\end{array}$ \\
\hline Wald_spatial_error & $\begin{array}{c}9.970^{* * *} \\
(0.002)\end{array}$ \\
\hline
\end{tabular}

Note: $* * *$, and $* * *$ represent significance at the $0.1,0.05$, and 0.01 levels, respectively. P-values are in brackets.

test and LR test are used. If the verification results reject these two hypotheses, the spatial Durbin model is selected. Likewise, if the result rejects $\mathrm{H}_{0}$ and the R_LMlag value is significant, the spatial lag model is selected. If the results rejected $\mathrm{H}_{1}$ and the R_LMerror value is significant, it is more appropriate to choose the spatial error model [30]. Therefore, relevant data were substituted in, and Wald and LR tests were conducted after the demonstration with the dual-fixed SDM model. The relevant results are shown in Table 5.

From the results, both Wald test and LR test of the spatial lag model were significant at the $1 \%$ level, thus rejecting the null hypothesis $\mathrm{H}_{0}$ and $\mathrm{H}_{1}$ that is, the spatial Durbin model cannot be simplified into a spatial lag model. Similarly, the LR test of spatial error model is significant at the level of 5\%, and Wald test is significant at the $1 \%$ level, indicating that spatial Durbin model cannot be simplified into spatial error model. Thus, this study uses the spatial Durbin model for empirical analysis.

\section{Spatial Durbin Model Estimation under Different Interaction Effects}

The spatial Durbin model of individual fixed effect, period fixed effect, and double fixed effect in the individual period are used for estimation, as shown in Table 6. First, as seen from the log-likelihood and R2 estimated from the model, the estimation results of the double-fixed model in the individual period are better than the other two models. This result again proves the superiority of the dual-fixed SDM model.

According to the estimation results of the three models, the spatial spillover effect of strategic emerging industrial agglomeration on the efficiency of China's green economy is positive. The estimated value passes the $1 \%$ significance mark. Taking model (3) as an example, every $1 \%$ increase in the industrial agglomeration coefficient will lead to a $0.0217 \%$ increase in green economic efficiency. Moreover, the coefficient of per capita GDP (AGDP), industrial structure (IND), and foreign investment (FDI) on the efficiency of green economy are positive; that is, they have a positive promoting effect. The coefficient of 
Table 6. Estimation results of the SDM model under different interaction effects.

\begin{tabular}{|c|c|c|c|}
\hline Variable & $\begin{array}{c}\text { Model (1) } \\
\text { Individual fixed effect }\end{array}$ & $\begin{array}{c}\text { Model (2) } \\
\text { Time fixed effect }\end{array}$ & $\begin{array}{c}\text { Model (3) } \\
\text { Individual period double fixed effect }\end{array}$ \\
\hline $\begin{array}{l}\text { The Main } \\
\text { InMAR }\end{array}$ & $\begin{array}{l}0.0538 * * * \\
(0.0509)\end{array}$ & $\begin{array}{c}0.136 * * * \\
(0.0472)\end{array}$ & $\begin{array}{l}0.0217 * * * * \\
(0.0351)\end{array}$ \\
\hline InAGDP & $\begin{array}{c}0.0683 * * \\
(0.0890)\end{array}$ & $\begin{array}{c}0.0528 * * \\
(0.126)\end{array}$ & $\begin{array}{c}0.0701 * * * \\
(0.0602)\end{array}$ \\
\hline InIND & $\begin{array}{c}0.129 * * \\
(0.106) \\
\end{array}$ & $\begin{array}{c}0.258 * * \\
(0.119) \\
\end{array}$ & $\begin{array}{c}0.0200 * * \\
(0.0763) \\
\end{array}$ \\
\hline InES & $\begin{array}{c}0.0301 * * * \\
(0.0400)\end{array}$ & $\begin{array}{c}0.0729 * * \\
(0.0417)\end{array}$ & $\begin{array}{c}0.0535 * * \\
(0.0283)\end{array}$ \\
\hline InFDI & $\begin{array}{l}0.0534 * \\
(0.0335)\end{array}$ & $\begin{array}{c}0.0904 * * * \\
(0.0329)\end{array}$ & $\begin{array}{c}0.0244 * * * \\
(0.0293)\end{array}$ \\
\hline InUR & $\begin{array}{c}0.0332 * * * \\
(0.239)\end{array}$ & $\begin{array}{l}0.111 * \\
(0.339)\end{array}$ & $\begin{array}{c}0.0309 * * * \\
(0.208)\end{array}$ \\
\hline $\begin{array}{c}\text { Wx } \\
\text { InMAR }\end{array}$ & $\begin{array}{c}0.0209 * * \\
(0.102)\end{array}$ & $\begin{array}{c}0.0204 * * \\
(0.0981)\end{array}$ & $\begin{array}{l}0.182 * * \\
(0.0917)\end{array}$ \\
\hline InAGDP & $\begin{array}{l}0.0557 * * \\
(0.107)\end{array}$ & $\begin{array}{l}0.0525 * * \\
(0.145)\end{array}$ & $\begin{array}{l}0.177 * * * \\
(0.0980)\end{array}$ \\
\hline InIND & $\begin{array}{c}0.00954 \\
(0.184) \\
\end{array}$ & $\begin{array}{c}0.149 \\
(0.206) \\
\end{array}$ & $\begin{array}{c}0.244 \\
(0.149) \\
\end{array}$ \\
\hline InES & $\begin{array}{l}0.0334 * \\
(0.0652) \\
\end{array}$ & $\begin{array}{c}0.151 * \\
(0.0948) \\
\end{array}$ & $\begin{array}{c}0.0584 * * * \\
(0.0451)\end{array}$ \\
\hline InFDI & $\begin{array}{l}0.0248 * \\
(0.0676)\end{array}$ & $\begin{array}{l}0.0985 * \\
(0.0574)\end{array}$ & $\begin{array}{c}0.000514 * * \\
(0.0385)\end{array}$ \\
\hline InUR & $\begin{array}{c}0.0975 * \\
(0.440)\end{array}$ & $\begin{array}{c}0.198 * * \\
(0.223)\end{array}$ & $\begin{array}{c}1.068 * * * \\
(0.382)\end{array}$ \\
\hline Spatial rho & $\begin{array}{c}0.0975 * * \\
(0.0694)\end{array}$ & $\begin{array}{c}0.151 * * * \\
(0.444)\end{array}$ & $\begin{array}{c}0.559 * * * \\
(0.152)\end{array}$ \\
\hline $\begin{array}{l}\text { Variance } \\
\text { sigma2_e }\end{array}$ & $\begin{array}{c}0.000537 * * * \\
(0.0000611)\end{array}$ & $\begin{array}{c}0.00536 * * * \\
(0.000959)\end{array}$ & $\begin{array}{c}0.000307 * * * \\
(0.0010476)\end{array}$ \\
\hline $\mathrm{N}$ & 150 & 150 & 150 \\
\hline $\mathrm{R}^{2}$ & 0.062 & 0.0816 & 0.098 \\
\hline Log likelihood & 351.6518 & 178.9866 & 389.3631 \\
\hline
\end{tabular}

Note: $* * *$, and $* * *$ represent significance at the $0.1,0.05$, and 0.01 levels, respectively. $Z$ values are in brackets.

energy structure (ES) and urbanisation (UR) on the efficiency of green economy is negative, producing a negative inhibiting effect.

\section{Spatial Effect Decomposition Analysis of Dual-Fixed SDM Model: Direct Effect, Indirect Effect, and Total Effect}

LeSage et al. believed that the traditional point estimation regression method will have errors when testing the spillover effect of spatial variables, and the coefficient of explanatory variables could be estimated by using the method of partial differentiation and decomposed into direct effect and indirect effect [31-32]. Therefore, the SDM model with a dual-fixed time-space can be further processed by partial differentiation; the relevant calculation results are shown in Table 7. Among them, direct effects can represent the impact of different explanatory variables in different regions on green economic efficiency, while indirect effects represent the impact of various explanatory variables in different regions on green economic efficiency in neighbouring regions. The total effect is the sum of the two; that is, the overall impact of all explanatory variables on green economic efficiency.

According to the correlation results in Table 7, specific analysis can be conducted on the spatial effect of strategic emerging industrial agglomeration on green economic efficiency.

The direct effect of strategic emerging industrial agglomeration on green economic efficiency is positive and significant at the level of $1 \%$, indicating that there is a spatial spillover effect. The direct effect is 0.139 ; that is, every $1 \%$ increase in strategic emerging industrial agglomeration can improve green economic efficiency by $0.139 \%$. This result matches the development status 
Table 7. Spatial decomposition of the SDM model under dual-fixed effecvb.bt in time.

\begin{tabular}{|c|c|c|c|}
\hline Variable & Direct effect & Indirect effect & Total effect \\
\hline InMAR & $0.1390 * * *(0.0465)$ & $0.0461(0.0730)$ & $0.0549 * *(0.0928)$ \\
\hline InAGDP & $0.0485 * *(0.0653)$ & $0.010 * * *(0.0731)$ & $0.148 * * *(0.0633)$ \\
\hline InIND & $0.0782 *(0.174)$ & $0.110 * *(-0.00854)$ & $0.0951 *(0.165)$ \\
\hline InES & $0.0516 * * *(0.0313)$ & $0.0190(0.0378)$ & $0.0342 *(-0.0706)$ \\
\hline InFDI & $0.0301 *(0.0263)$ & $0.00958 *(0.0279)$ & $0.0350 *(0.0168)$ \\
\hline InUR & $0.762 * *(0.226)$ & $0.113(0.314)$ & $0.649 * * *(0.258)$ \\
\hline
\end{tabular}

Note: ${ }^{*}{ }^{* *}$, and $* * *$ represent significance at the $0.1,0.05$ and 0.01 levels, respectively. $Z$ values are in brackets.

of China's strategic emerging industries. Due to the development of strategic emerging industries, China has been making breakthroughs in the field of emerging technologies. New technologies should help improve the overall operational efficiency of the industry, reduce resource waste and pollution, and improve the green efficiency level of the region. Meanwhile, energy conservation and the environmental protection industry are important sub-industries of strategic emerging industries. Including Beijing, Tianjin, and Shanxi, 23 provinces and cities have formulated policies to encourage the development of energy conservation and environmental protection, providing important support for accelerating the concentration of the energy conservation industry. Strategic emerging industries will accumulate knowledge, technology, talents, information, and other elements, accelerate the elimination of backward production capacity, cause scale effect and technology agglomeration effect, and increase the level of regional green efficiency.

Meanwhile, from the perspective of the indirect effect of the strategic emerging industrial agglomeration, its coefficient is negative; thus, it fails the significance test, indicating that spatial spillover of China's strategic emerging industry is not obvious. This phenomenon is closely related to the strategic emerging industries being at the beginning of the industrial life cycle. Currently, although China's strategic emerging industries have good momentum, they still take a small proportion in the total industrial output value, and the localization effect of the industrial agglomeration is obvious, indicating that it has not formed important influence on the surrounding areas. In the current stage, the indirect effect of the strategic emerging industries agglomeration on the area around green economic efficiency is uncertain, and the industry radiation effect is not significant. Therefore, further promoting strategic emerging industries agglomeration and green economic efficiency to drive the surrounding area is of great significance, especially in the Yangtze River economic belt, such as the Pearl River delta in the BeijingTianjin-Hebei region. However, from the perspective of the overall effect, strategic emerging industrial agglomeration has a positive spatial spillover effect on green economic efficiency, which is significant at the $5 \%$ level.

\section{Analysis of the Influence of Control Variables on Green Economic Efficiency}

(1) The direct effect coefficient of economic development level (AGDP) to green economic efficiency is 0.0485 , which has a positive spatial spillover. The higher the economic level, the better the economic efficiency. This result shows that the quality of China's economic development continues to improve, and the original economic development at the expense of the environment and resources is changing. Meanwhile, the indirect effect of the economic development level is also significantly positive, and regional economic development has a positive impact on the green economic efficiency of neighboring regions. (2) The direct and indirect effects of the industrial structure (IND) can be divided into positive and negative correlations at the 5\% significance level. With the continuous adjustment and optimization of China's industrial structure, increasing the proportion of tertiary industry and eliminating the traditional secondary industry of some backward industries are conducive to improving the efficiency of the regional green economy. Meanwhile, China's industrial structure has a spatial spillover, and the optimization of industrial structure between regions will produce a positive effect. (3) The total effect and direct effect of energy structure (ES) on green economic efficiency are negative, and the indirect effect is not significant through the significance test. This result shows that China's coal-based energy structure has caused serious environmental pollution and hindered the green development of the economy. At the same time, the energy structure difference has no obvious effect on the green economic efficiency between regions. (4) The direct effect of foreign direct investment (FDI) on the efficiency of green economy is significantly positive ( $5 \%$ level), the indirect effect is significantly negative $(10 \%$ level), and the total effect is significantly positive ( $5 \%$ level). Foreign investment often brings advanced technology, knowledge, and firstclass talents, which can help build strategic emerging 
enterprises that bring economic benefits in a short time, drive the emergence of upstream and downstream industrial chains, and promote green economic efficiency. At the same time, the indirect effect of foreign investment is negative. The possible reason is that in the short term, the increase in foreign investment will attract talents and funds from surrounding areas, or lead to horizontal competition among surrounding enterprises, thus affecting the green economic efficiency of surrounding areas. (5) The urbanization level (UR) has a significant inhibiting effect on the green economic efficiency; the direct effect, and total negative effect, and indirect effect are not significant. As China's urbanization continues, a large number of polluting enterprises will move to second- and third-tier cities, where automobile exhaust fumes are increasing and household waste pollution is severe. The urbanization level will have a negative impact on green economic efficiency. However, the impact of urbanization between neighboring regions is not obvious, which is consistent with the status quo in China.

\section{Conclusions}

This study expands the traditional theory of industrial agglomeration by introducing the spatial econometric model and green efficiency theory and studies the spatial spillover effect of industrial agglomeration on the green efficiency of a regional economy. First, this study measures the effect of China's strategic emerging industrial agglomeration on regional green economic efficiency. We found that, first, China's strategic emerging industry cluster shows a tendency to decrease from east to west on geographical spatial agglomeration, which is consistent with the level of regional economic development. Second, the green economic efficiency in most parts of China is below the frontier of production, and there are obvious redundant inputs of labor, capital, and energy, while different input factors contradict the needs of the ecological environment. Third, the direct and total effects of strategic emerging industrial agglomeration on the green economic efficiency are significantly positive, while the indirect effects are not significant. The scale effect of strategic emerging industrial agglomeration is helpful for improving regional green economic efficiency; however, it has little impact on neighboring regions. Fourth, the effects of economic development level, industrial structure, energy structure, foreign direct investment, and urbanization level on green economic efficiency are heterogeneous.

Based on these findings, we propose that, first, the agglomeration and development of strategic emerging industries be supported, and the "scale effect" expanded. The proportion of strategic emerging industries in the industrial structure must be increased, and a new pattern of industrial development supported by technology, capital, policies, and finance must be created. China's central and western regions can achieve industrial upgrading by developing strategic emerging industries. Next, strategic emerging industries should enhance regional cooperation and upgrade to exert a "diffusion effect." The industrial chain should support the development of strategic emerging industries, a cooperative relationship between upstream and downstream regions should be created, and the efficient flow of core elements such as talents, technology, information, and logistics within the industry should be accelerated. It is necessary for the Beijing-Tianjin-Hebei region, the Yangtze River economic belt, and the Guangdong-Hong Kong-Macao Greater Bay area to build a strategic emerging industry development system based on industrial synergy. Finally, resources for the regional green economy should be properly allocated, and the multiplier effect should be strengthened. All regions should make a priority the elimination of backward production capacity. The original economic development model should be changed, and more attention must be paid to high-quality, sustainable, and green economic growth; ecological and environmental protection; and the optimal allocation of all elements of green economic growth.

\section{Acknowledgments}

This research was funded by the National Social Science Fund Project (No. 15BGL056), a fund project for the forward-looking development strategy of basic scientific research operating expenses of central universities (No. NW2019002), Tianjin philosophy and social science planning project (No. TJGLQN19XSX-006) and CAAC environmental and sustainable development research center (think tank) open fund (No. CESCA2019Y02).

\section{Conflicts of Interest}

The authors declare no conflicts of interest.

\section{References}

1. ALFREF M. Principles of Economics. Macmillan Press: London, England, 32, 1961.

2. MICHAEL E.P. Competitive Strategy. Free Press: New York, USA 165, 1999.

3. ARTHUR J. External Trade in Developing Economies NBER, WorkingPaper. 11, 9, 2001.

4. PAN W., LIU Q. Industrial agglomeration and regional economic growth in China's manufacturing industry research based on data of Chinese industrial enterprises. Journal of Tsinghua University (philosophy and social sciences edition). 27 (01), 137-147+161, 2012.

5. SUN X., ZHOU L. Diversification, specialization, city size and economic growth - an empirical test based on China's 
prefecture-level city panel data. Journal of management engineering. 27 (02), 71, 2013.

6. WANG X., XIE X. Study on the employment effect of regional integration from the perspective of economic growth and industrial agglomeration - an empirical study based on the Yangtze river economic belt. Exploration of economic issues. (06), 84, 2018.

7. CHEN L., SUN B., XIE X. Spillover effect of industrial agglomeration on economic growth - from the perspective of new economic geography. Journal of capital university of economics and business. (04), 42, 2019.

8. PEARCE D., MARKANDYAA, B.E. Blueprint1: for a green ecomomy. Earthscan: New York, USA, 1989.

9. WANG J., GENG, J. Measurement and empirical analysis of China's green economy efficiency. Economic issues. (04), 52, 2014.

10. HUA X., WANG H., QIU G. Jiangsu green development transformation: based on green Efficiency and Environmental Total Factor Productivity. Discussion on Modern Economy. (07), 18, 2018.

11. LIU T., HAN D. Research on eco-economic efficiency and its measurement method of enterprises based on environmental management. Business research. (10), 34, 2018.

12. SHI B., XU N., LIU M., DENG, M. Influences and channels of financial agglomeration on urban green economic efficiency - an empirical analysis based on 249 cities at the prefecture level and above in China. Technology economy. (8), 87, 2018.

13. GONG X., LI M., ZHANG H. Whether OFDI improves the efficiency of industrial green innovation in China an empirical study based on the effect of agglomeration economy. International trade issues. (11), 127, 2017.

14. QIAN L. Spatial measurement of green economic efficiency and its influencing factors in Chinese cities. Exploration of economic issue. (8), 160, 2018.

15. QIAN Z., LIU X. Regional differences and convergence of green economy efficiency in China. Journal of Xiamen University (philosophy and social sciences edition). 1, 110, 2014.

16. HU Z., LI Y., LIU Y. Regional differences and convergence of green technology efficiency in China. Soft science. 31 (8), 1, 2017.

17. TONE K. A slacks - based measure of efficiency in data envelopment analysis. Eur J Oper Res., 130, 429, 2001.

18. HOOVER E. The measurement of industrial localization. Rev Econ Stat. 18 (4), 162, 1936.

19. CLIFF A., HAGGETT P. The impact of GIS on epidemiological mapping and modelling. Longley P, Batty M. Spatial Analysis: Modelling in a GIS Environment. Geoinformation International: Cambridge, 321, 1996.
20. WU C., WEI D., HUANG X., Bowen CHEN B., Economic transition, spatial development and urban land use efficiency in the Yangtze River Delta, China. Habitat International, 63, 67, 2017.

21. GUO I., LEE H., LEE D. Lee, An integrated model for slack-based measure of super-efficiency in additive DEA. Omega, 67, 160, 2017.

22. REN Y., WANG C., ZHANG S., YU C. High-tech industrial agglomeration, spatial spillover and green economic efficiency - dynamic spatial Durbin model based on Chinese provincial data. Systems engineering. 37 (01), 24, 2019.

23. LIN R., LIU Y. Super-efficiency based on the directional distance function in the presence of negative data. Omega, 85, 26, 2019.

24. TANG J., FANG Y., ZHANG X., TANG Y. Research on the spatial spillover effect of industrial agglomeration and regional economic growth - based on the spatial Durbin model of China's provincial manufacturing industry. Statistics and information BBS. 33 (10), 56, 2008.

25. LIU X., LI L., GE J., TANG D., ZHAO S. Spatial Spillover Effects of Environmental Regulations on China's Haze Pollution Based on Static and Dynamic Spatial Panel Data Models. Polish Journal of Environmental Studies. 28 (4), 2231, 2019.

26. CHEN X., SHAO S., TIAN Z., XIE Z. YIN P. Impacts of air pollution and its spatial spillover effect on public health based on China's big data sample. Journal of Cleaner Production, 142, 915, 2017.

27. SONG J., FENG Q., WANG X., FU H., JIANG W., CHEN B. Spatial Association and Effect Evaluation of $\mathrm{CO}_{2}$ Emission in the Chengdu-Chongqing Urban Agglomeration: Quantitative Evidence from Social Network Analysis. Sustainability. 11 (1), 1, 2019.

28. ELHORST J.P. Dynamic spatial panels: models, methods, and inferences. J Geogr Syst. 14 (1), 5, 2012.

29. YANG S. WANG L. Economic association, spatial overflow and economic growth of urban agglomeration in the Yangtze River delta - an empirical study based on spatial panel econometric model. Systems engineering. 35 (11), 99, 2017.

30. BURIDGE P. Testing for a common factor in a spatial autoregression model. Environ Plan A. 13 (7), 795, 1981.

31. LESAG J.P., PACE R.K. Introduction to Spatial Econometrics. CRC Press Talor\&Francis Group: Boca Raton, US, 2009.

32. WANG X., LI M. The Spatiotemporal Characteristic of Carbon Emissions from China's Power Sector and its Determinants: A Spatial Econometric Analysis. Polish Journal of Environmental Studies, 28 (5), 3919, 2019. 